\title{
A Simultaneous Mobilization of Four Impacted Upper Incisors in a Case of an Adolescent Patient with Cleidocranial Dysplasia (CCD)
}

\author{
Bechtold TE ${ }^{1,2 *}$, Lee KJ ${ }^{2}$, Park YC ${ }^{2}$, Berneburg M'1 , Göz GR ${ }^{1}$ \\ ${ }^{1}$ Department of Orthodontics, Eberhard-Karls-University, Tübingen, Germany \\ ${ }^{2}$ Department of Orthodontics, Yonsei University, Seoul, Korea
}

\begin{abstract}
Introduction: Cleidocranial dysplasia (CCD) is often attended by a considerable number of supernumerary teeth combined with impaction of sometimes all permanent teeth. To help these patients obtain an esthetically pleasing and functional dentition, eruption of an appropriate number of permanent teeth should ideally be brought about, while all other teeth should be removed. The simultaneous traction of several neighboring teeth into the same direction is associated with biomechanical challenges. This report illustrates how these difficulties were solved in a specific treatment case.
\end{abstract}

Findings and diagnosis: A 9-year-old boy presented with delayed tooth eruption. Major concern of the patient was the edentulous maxillary anterior segment. Clinical manifestation was confined to all deciduous canines and molars in both jaws and to the permanent mandibular central incisors. Radiographic examination revealed the impaction of all remaining permanent teeth as well as 20 supernumerary teeth and four third-molar buds. Cephalometric analysis revealed a tendency for skeletal class III in conjunction with a horizontal growth pattern.

Treatment progress and outcomes: Utilizing a custom-planned appliance, four completely impacted maxillary incisors could be moved to esthetically and functionally acceptable positions within 8 months. The appliance used was supported exclusively by the maxillary deciduous teeth and the palate. Thanks to biomechanical considerations, the position of the anchor teeth could be fully preserved.

Conclusions: Simultaneous mobilization of multiple teeth requires a customized approach that does justice to each patient's individual situation. Meticulous treatment planning can prevent adverse effects even without the use of skeletal anchorage methods.

Keywords: Dysostosis cleidocranialis; Impacted teeth; Supernumerary teeth; Mobilization; Orthodontic custom appliance; Biomechanics

\section{Introduction}

Cleidocranial dysplasia (CCD) was first described by Scheuthauer [1] in 1871, with a second major contribution made in 1898 when Marie and Sainton [2] demonstrated both the hereditary nature of CCD and irregularities in tooth development. Following comprehensive anatomical examinations by Hultkrantz [3], several studies were published about the morphology [4-6], pathophysiology [7-9], and treatment [10-12] of CCD.

Today CCD is known to be an (autosomal dominant) hereditary malformation syndrome that occurs in approximately one per million people $[13,14]$ and whose symptoms are highly variable $[9,13]$. Its stereotypical form would involve a short stature, a brachycephalic facial structure, and the presence of bone hypoplasia, notably affecting connective tissue bone. The clavicular defects typically present allow the joining of the shoulders before the patient's chest, and ossification of the cranial fontanelles is extremely delayed [15]. The most striking characteristics from an orthodontic viewpoint include a tendency for pseudoprognathism and the presence of extreme polyodontia with impaction of (sometimes all) permanent teeth. The number of supernumerary teeth averages 0-12 [16], but may be much higher [17].

The symptoms of CCD are pronounced but benign, without involving any mental or physical handicaps. Treatment of the entire organism is therefore not an objective $[18,19]$. Therapy remains confined to the facial and oral structures and is provided as dental treatment or, ideally, as orthodontic-surgical treatment.

Three concepts of treating CCD patients (including children) are well known: the Toronto-Melbourne concept [20,21], the Belfast-
Hamburg concept [22,23], and the Jerusalem concept [24,25]. While the former two approaches rely on a radical course of surgery without active mobilization, the Jerusalem concept relies on orthodontic force application and is particularly well suited to win patients' trust and motivation by offering successful outcomes using a stepwise approach. These active orthodontic measures no doubt improve the success rates of the treatment.

Especially the retardation of tooth movement which has been proved to be a consequence of the haplo insufficiency of the Runx2 gene involving transcription factor CBFA1 [26-29] makes anchorage an even more important issue; unwanted side-effects could be increased as compared to healthy individuals. That is why in tooth traction of CCD patients biomechanical properties of the often individually planned appliances must be thought through very carefully.

This article reports on a clincal case of a 9-year-old boy with CCD revealing biomechanical effects of different parts of the appliance used for this patient.

*Corresponding author: Dr. Till Edward Bechtold, Eberhard-Karls University Tübingen, Dental Hospital, Department of Orthodontics, Osianderstr. 2-8, D-72076 Tübingen, Germany. Phone: +49 7071 29-85788; Email: till.bechtold@med.uni-tuebingen.de

Received January 10, 2014; Accepted February 08, 2014; Published February 10, 2014

Citation: Bechtold TE, Lee KJ, Park YC, Berneburg M, Göz GR (2014) A Simultaneous Mobilization of Four Impacted Upper Incisors in a Case of an Adolescent Patient with Cleidocranial Dysplasia (CCD). Dentistry 4: 210 doi:10.4172/2161-1122.1000210

Copyright: (c) 2014 Bechtold TE, et al. This is an open-access article distributed under the terms of the Creative Commons Attribution License, which permits unrestricted use, distribution, and reproduction in any medium, provided the original author and source are credited. 


\section{Case History}

The patient presented at the Department of Orthodontics (University of Tübingen, Germany) at 9 years and 4 months. He was mainly concerned about his missing maxillary anterior teeth. The intraoral situation revealed that the transition from deciduous to permanent dentition was atypical of the boy's age. Orthopantomography was obtained for causative assessment. Based on the finding of polyodontia, additional documentation was created to initiate orthodontic treatment.

\section{Diagnosis}

Analysis of the documentation yielded the following findings:

- Photostat analysis (as described by Schwarz [30]) demonstrated an enlarged lower face and a posteriorly slanted anterior face (Figure 1).
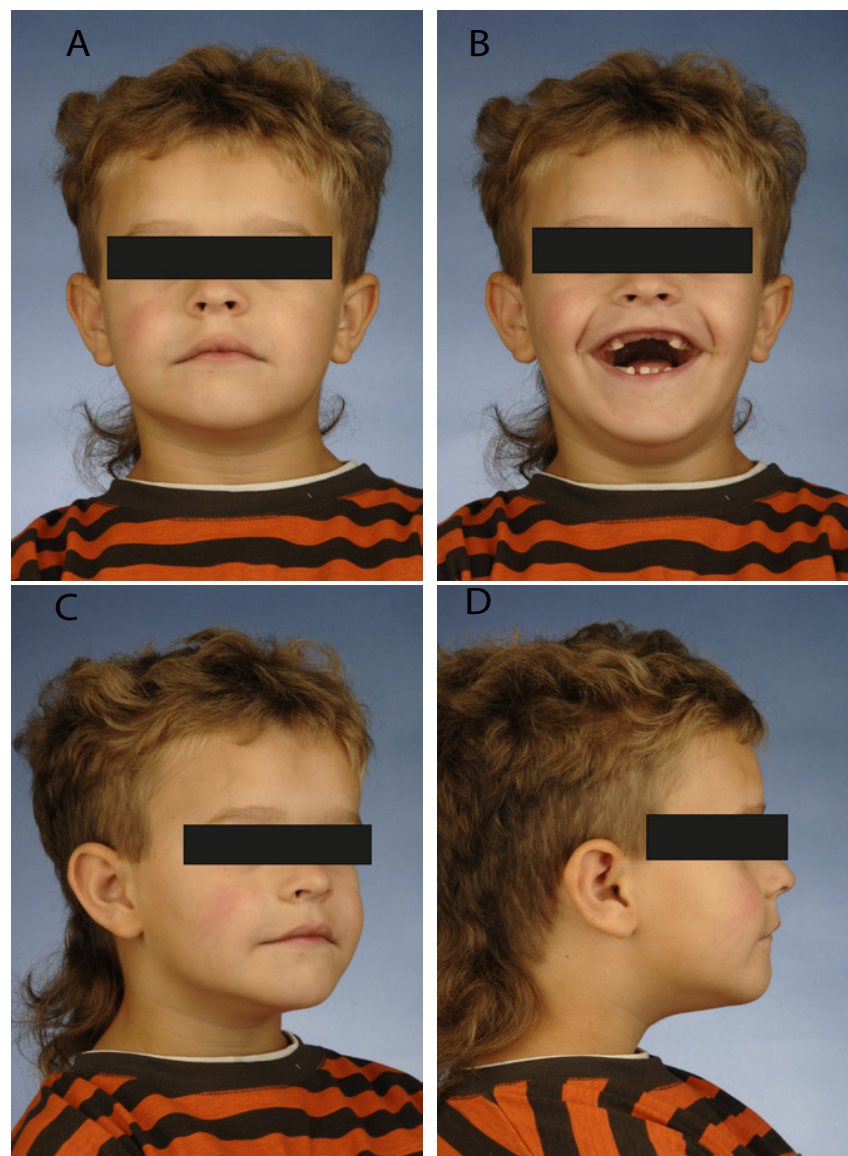

Figure 1: Extraoral photographs before treatment: frontal view, serious (a); frontal view, smiling (b); halfprofile from righthand side (c); profile from righthand side $(\mathrm{d})$.

- The maxillary arch included deciduous teeth $55,54,53,63,64$, 65 with grade 0 mobility. The transversal dimension was approximately normal (Figure 2). No permanent teeth were visible.

- The mandibular arch included deciduous teeth $75,74,73,83$, 84,85 with grade 0 mobility (Figure 2). Teeth 31 and 41 were mesially rotated and completely erupted; despite edentulous spaces at sites 32 and 42 , they revealed a tendency for initial crowding. Because of this, the mandible was narrower transversally than the maxilla, primarily

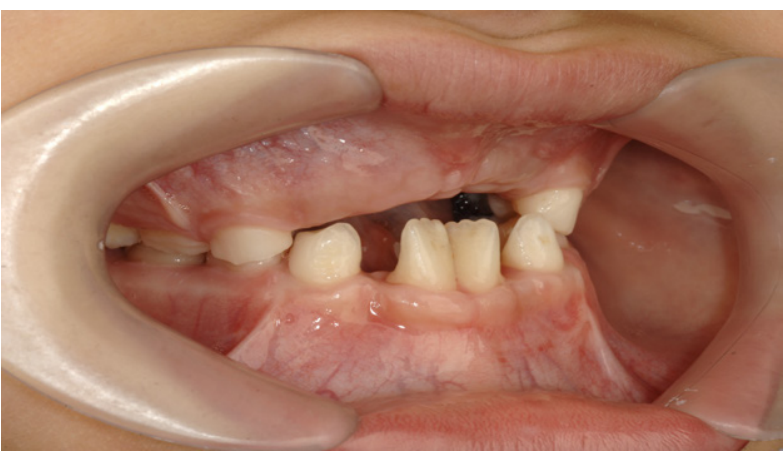

Figure 2a: Occlusion from righthand side.

due to mesial positioning of the mandibular deciduous teeth.

- The bilateral finding of mesial occlusion by roughly $4 \mathrm{~mm}$ was largely attributable to anterior migration of the mandibular posterior teeth. Because of the missing upper incisors overjet and overbite were not measurable.

- A total of 19 supernumerary teeth, including the third molars, were identified throughout the four quadrants in the baseline panoral radiograph (Figure 3). In the cone-beam computed tomography (CBCT) scan, these supernumerary teeth are indicated by white arrows (Figure 3). Since this scan was obtained approximately 1 year after the baseline orthopantomogram, 2 of these 19 supernumerary teeth (whose original positions are indicated by white circles) had been removed by that time. Another 5 supernumerary teeth were identified with the help of the CBCT scan. Four of them are indicated by red arrows. The remaining one was fully obliterated by tooth 26 and is indicated by a yellow arrow. In summary, therefore, the patient had 24 supernumerary teeth at the outset of treatment, including all four third molars.

- The lateral cephalometry obtained at baseline revealed a tendency for skeletal class III and a horizontal growth pattern (Figure 3). Conclusions about dental characteristics were restricted due to having the lower central incisors as the only erupted permanent teeth.

- As a non-dental finding, it was noticed that both shoulders could be joined before the patient's chest (Figures $4 \mathrm{a}$ and $\mathrm{b}$ ).

From these symptoms we concluded that the patient had Cleidocranial dysplasia (CCD). Indicating its hereditary character, his mother told us that she had similar symptoms; her supernumerary teeth had been removed when she was younger.

\section{Objectives and Treatment Planning}

The overall treatment objective was to mobilize a complete set of permanent teeth and to adjust them in a functional and esthetic fashion while removing all supernumerary teeth if possible.

Treatment was started, as dictated by the patient's main concern, by mobilizing the maxillary anterior teeth. Subsequently, additional permanent teeth were to be mobilized afterwards.

\section{Biomechanical Considerations for Phase I Treatment}

The deciduous canines and molars were to be used for anchorage of the appliance designed to mobilize the permanent maxillary anterior teeth. While there were no plans to preserve these teeth in the long term, it was necessary to consider potential side effects with respect to the underlying tooth buds. 


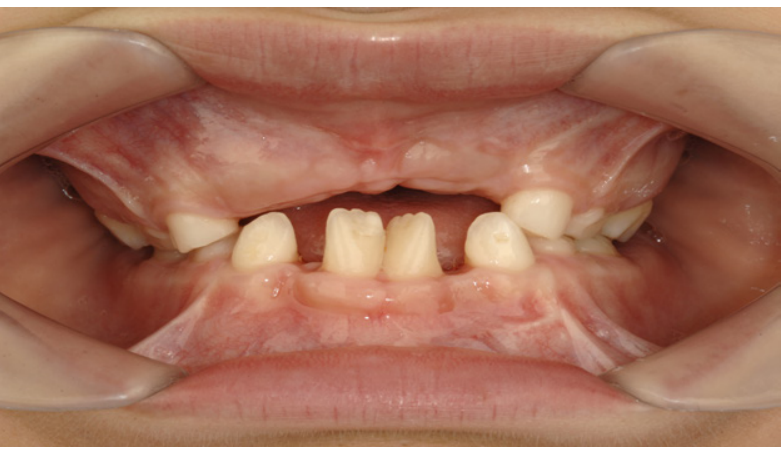

Figure 2b: Occlusion frontal.

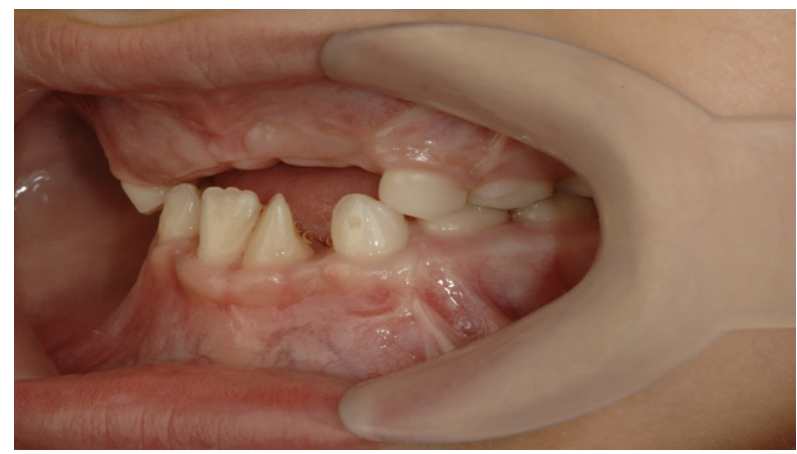

Figure 2c: Occlusion from lefthand side.

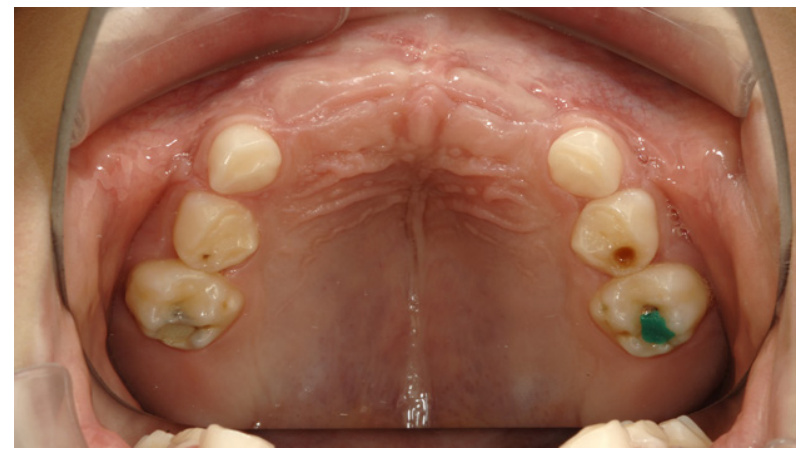

Figure 2d: Maxillary arch.

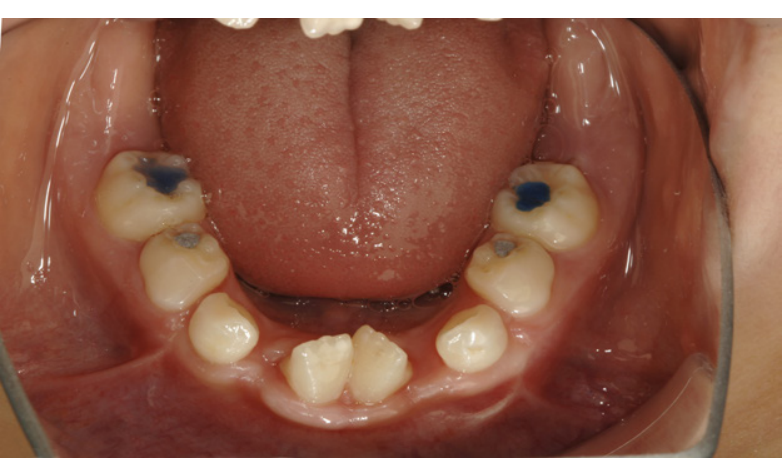

Figure 2e: Mandibular arch
The appliance was designed as follows:

A rigid archwire was attached on the vestibular side of the prospective maxillary dental arch. The four impacted anterior teeth, following their exposure and bonding from a vestibular approach, were pulled in a caudoventral direction against this archwire (Figures 5a).

Being the largest teeth available, the second deciduous molars were

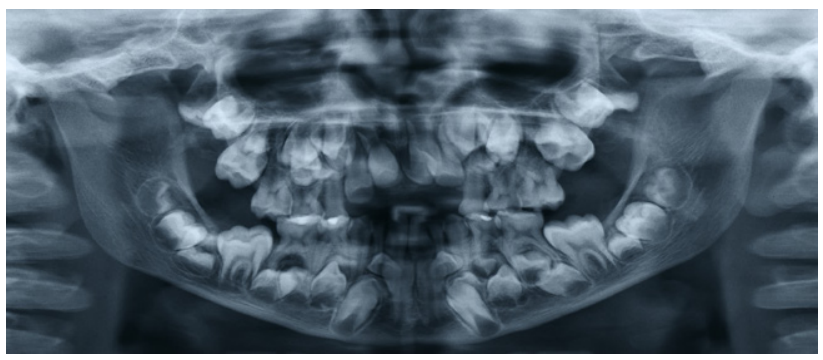

Figure 3a: Initial orthopantomogram.

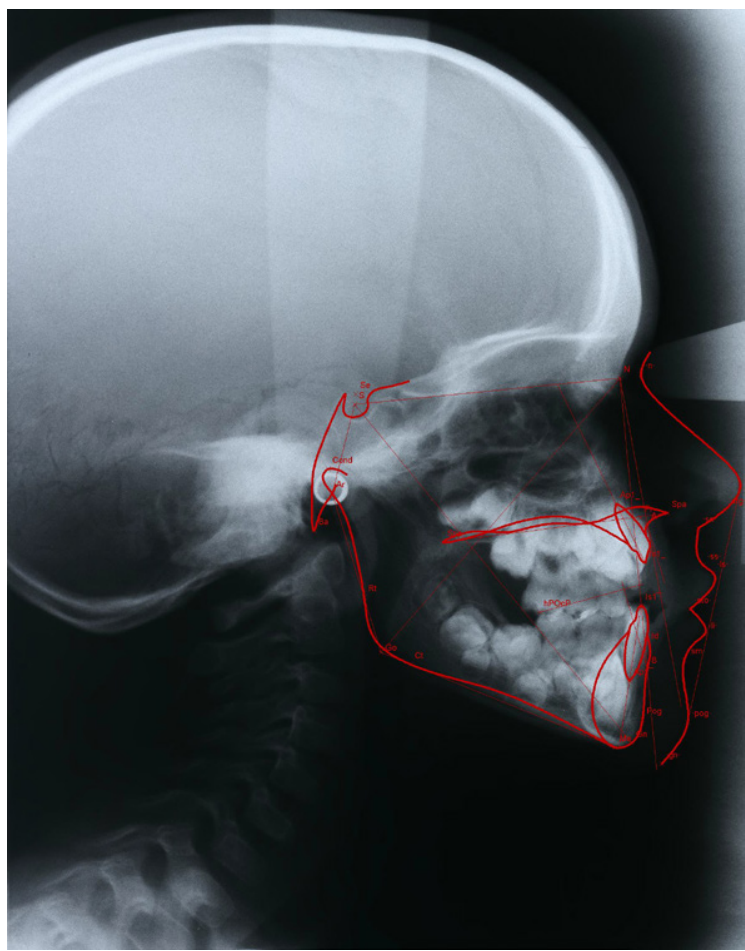

Figure 3b: Initial lateral cephalogram.

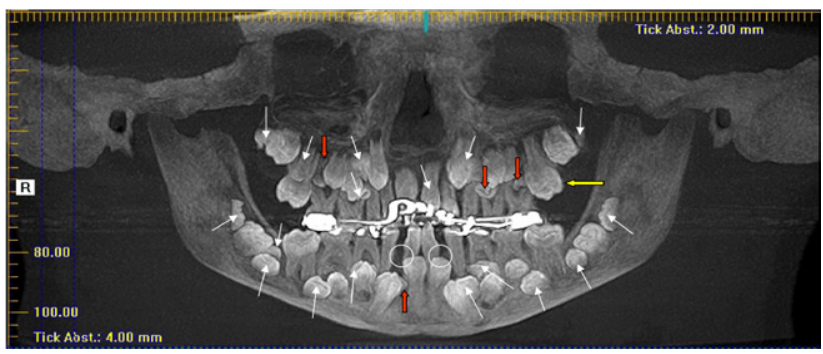

Figure 3c: Cone-beam CT just after treatment start. 


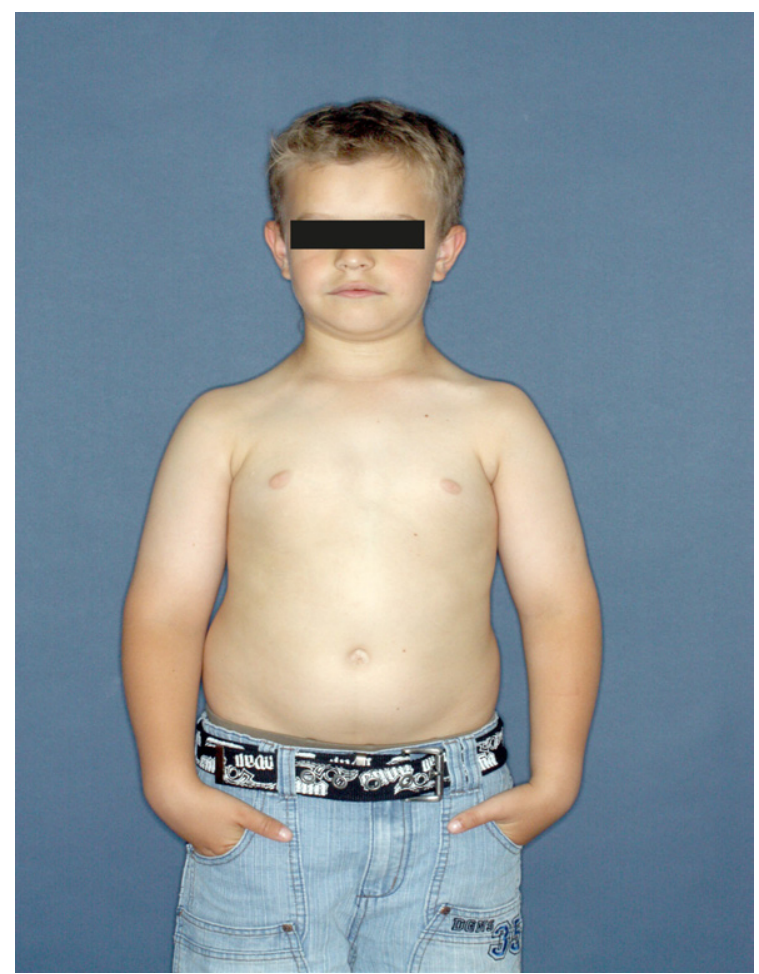

Figure 4a: Clinical view of the clavicle-related symptom: normal shoulder position.

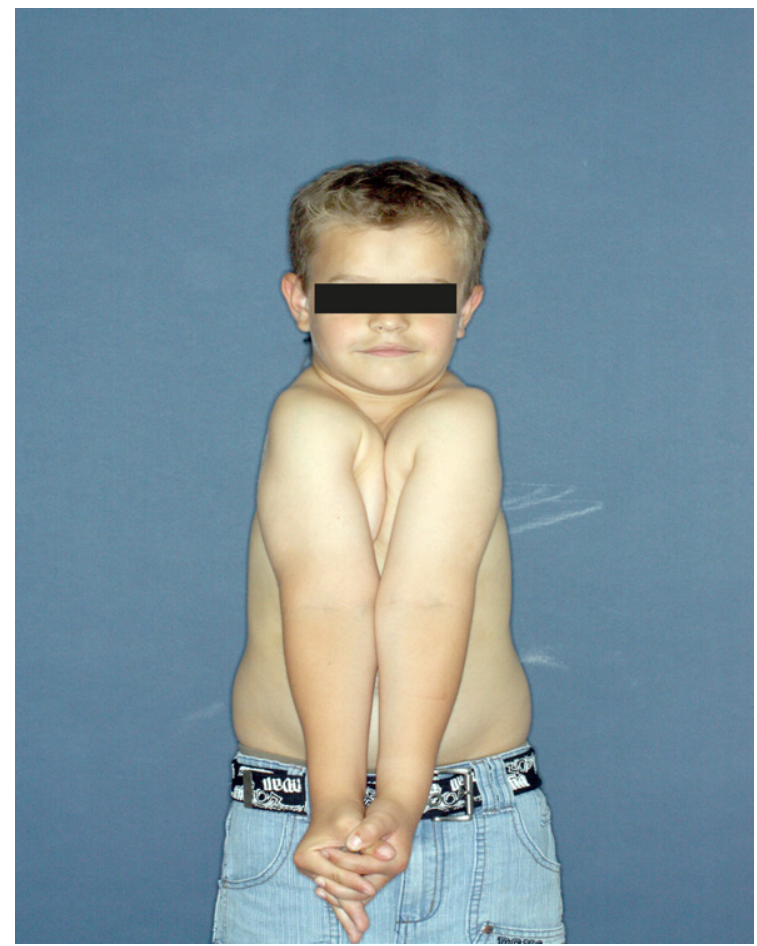

Figure 4b: Shoulders joined before the patient's chest.

fitted with the molar bands needed to attach the vestibular archwire. Used in isolation, this attachment mode would place the center of rotation of the appliance at the crowns of the second deciduous molars. The archwire was also attached to the deciduous canines for anterior

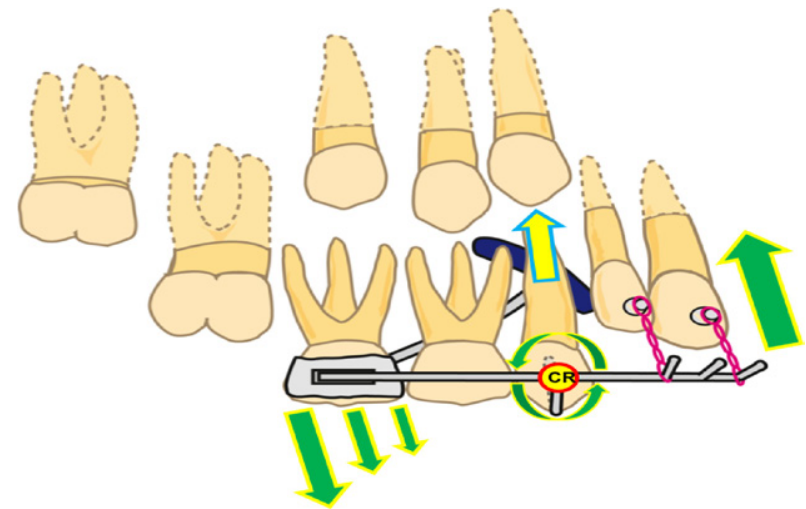

Figure 5a: Templates of the appliance: lateral view including force directions.

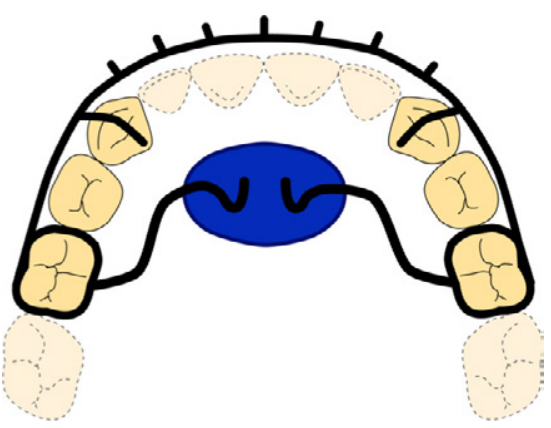

Figure 5b: Occlusal view.

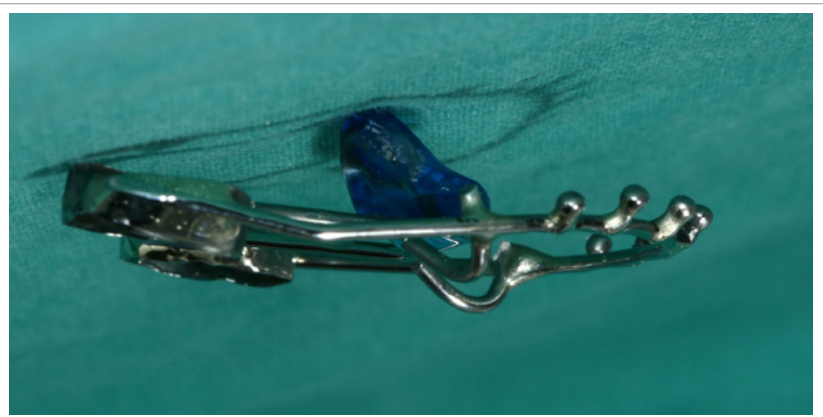

Figure 6a: The appliance: lateral view.

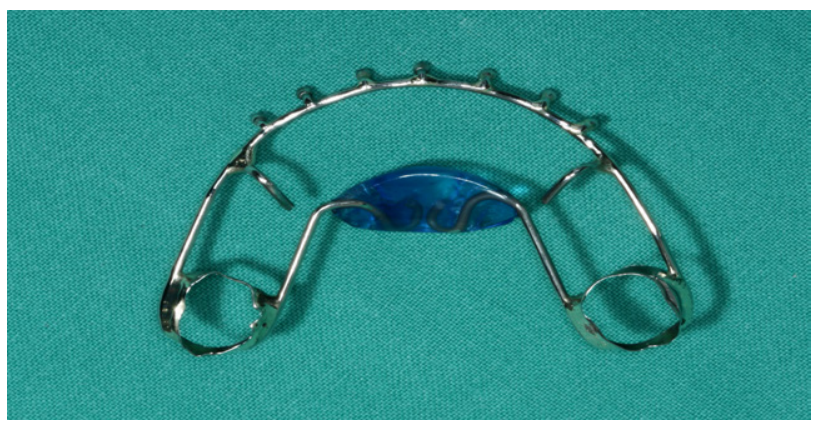

Figure 6b: Occlusal view. 
support, increasing durability and effectiveness. This would shift the center of rotation (CR) toward the canines (Figures 5a). As the unfavorable anatomic shape and advanced attrition of the deciduous canines (Figures 2a-c) precluded the use of bands, it was decided to apply overlays to the deciduous canines, which would serve the same purpose as bands with regard to the center of rotation (Figures 5a).To compensate for the resultant intrusive force acting on the deciduous canines, a palatal support was added to the appliance at the level of the canines (Figures $5 \mathrm{a}$ and $\mathrm{b}$ ).

Seven blunt hooks were welded to the anterior segment of the vestibular archwire to offer selective variation of the tensile direction along the wire. The finished appliance is shown in Figures $6 a$ and $b$.

\section{Treatment Progress and Results}

Treatment was started with surgical exposure of teeth 12,11, 21 and 22 when the patient was 9 years and 6 months old, adhesively chaining buttons to the affected teeth. The orthodontic appliance was inserted one week after the surgical procedure (Figures $7 \mathrm{a}$ and $\mathrm{b}$ ).

As soon as 4 weeks later, a markedly successful effect on the maxillary lateral incisors was noted (Figures $8 \mathrm{a}$ and $\mathrm{b}$ ).

When $5 \frac{1}{2}$ months had elapsed after the beginning of mobilization, tooth 11 was in the process of erupting, while tooth 21 was not clinically visible (Figures $9 a$ and $b$ ).

Tooth 21 began erupting after roughly 7 months and more than half of its crown was visible only 1 week thereafter.

After 8 months (Figures 10a and b), all four maxillary incisors were erupted to the point where the appliance could be removed (Figures 11a and b). The mobilized teeth exhibited grade II mobility at that point and had become so sensitive that the clinician decided against removing the

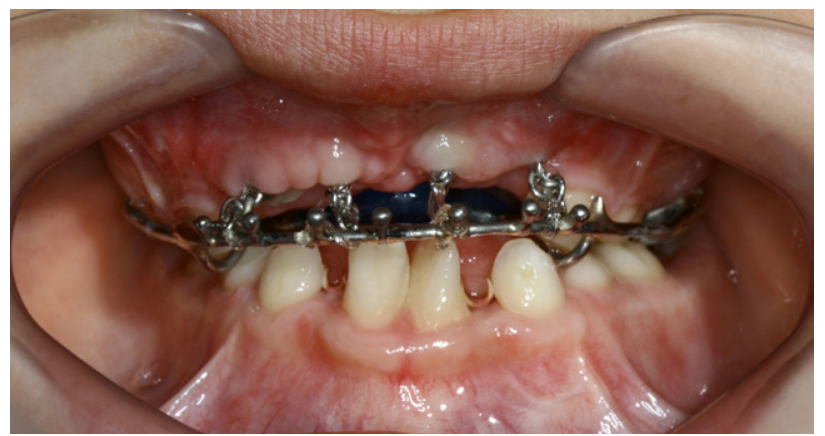

Figure 7a: Situation at treatment start: frontal view.

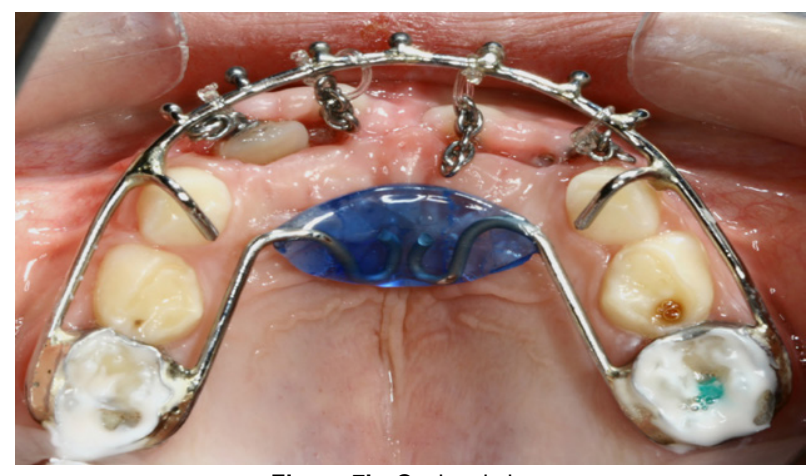

Figure 7b: Occlusal view.

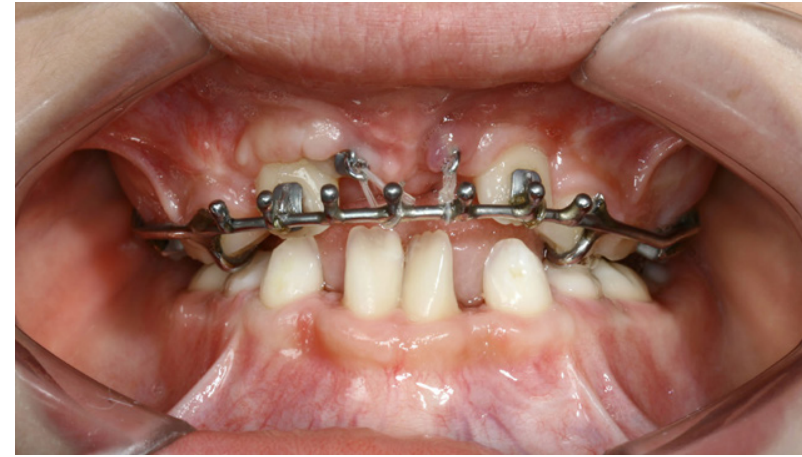

Figure 8a: Situation 4 weeks after treatment start: frontal view.

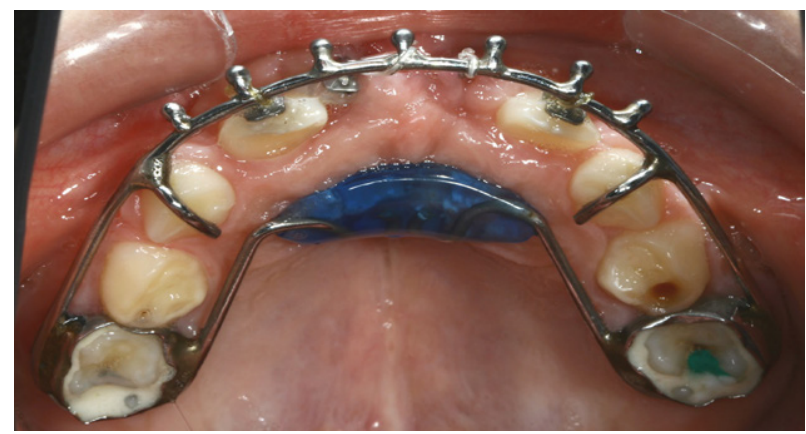

Figure 8b: Occlusal view.

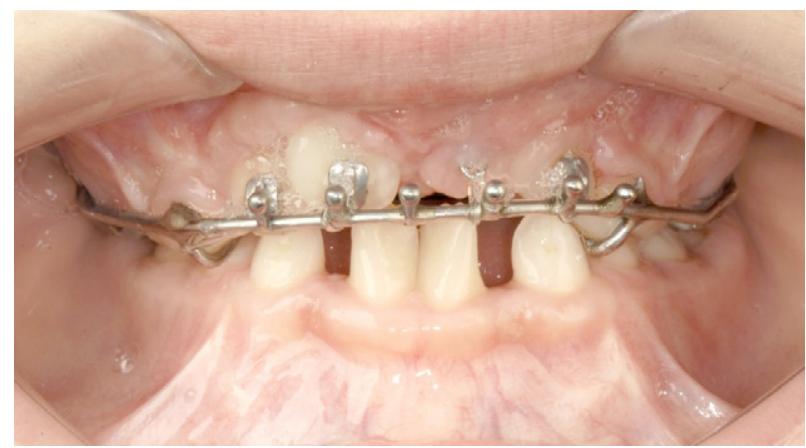

Figure 9a: Situation $5 \frac{1}{2}$ months after treatment start: frontal view.

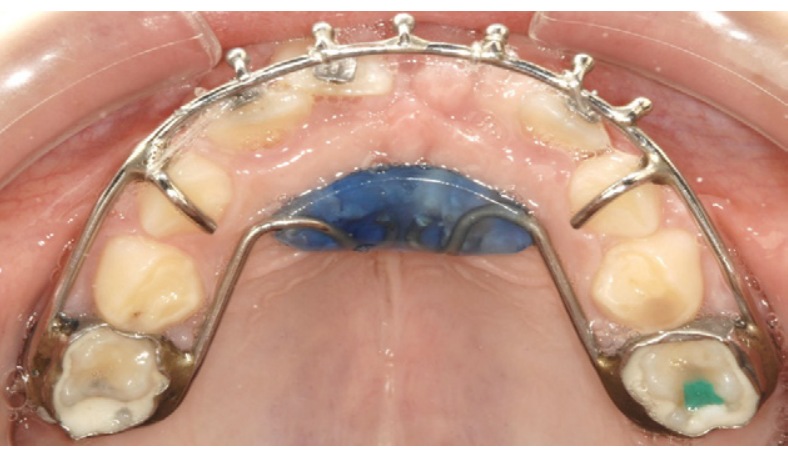

Figure 9b: Occlusal view. 


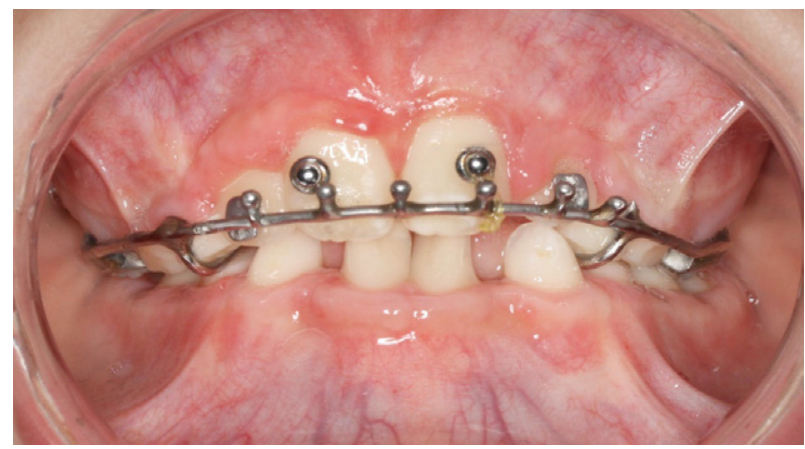

Figure 10a: Situation 8 months after treatment start, before removal of the appliance: frontal view.

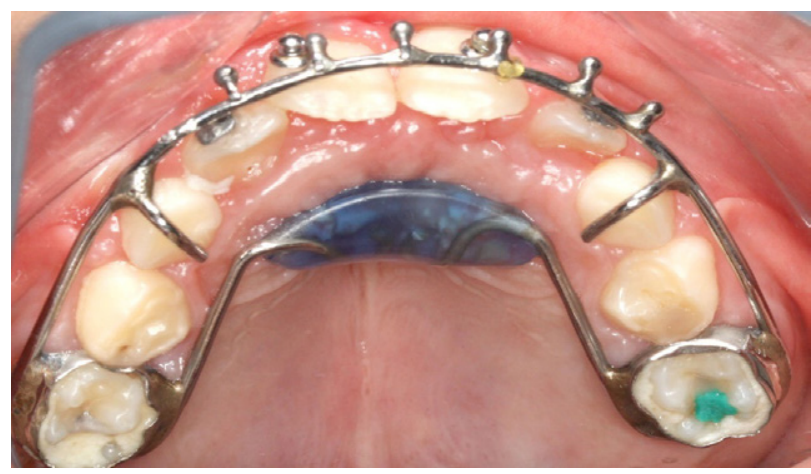

Figure 10b: Occlusal view.

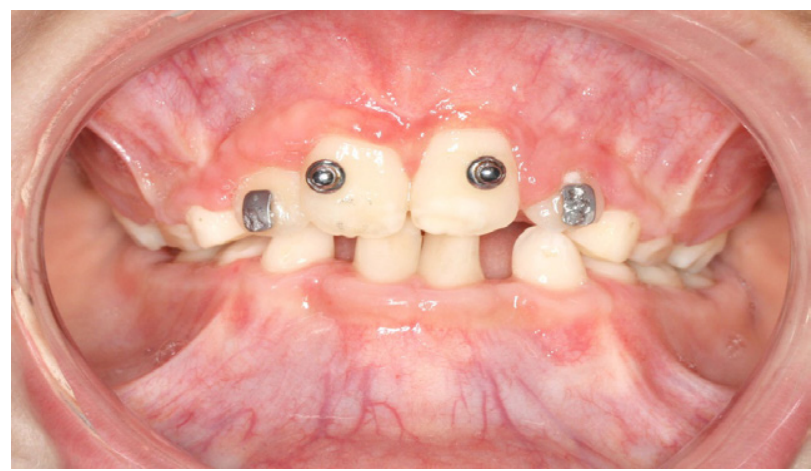

Figure 11a: Situation 8 months after treatment start, after removal of the appliance: frontal view.

adhesive buttons at this point (Figure 12a). Figure 12b shows the good state of the dental roots after mobilization though. During the following 6 weeks all four upper incisors attained physiological mobility, not needing any therapeutic retention procedure.

\section{Discussion}

This case report illustrates the mobilization of four impacted anterior teeth by a custom-designed fixed orthodontic appliance as a first stage in the treatment of a child with cleidocranial dysostosis (CCD).

Up to the second half of the 20th century, dental treatment of patients with CCD was confined to preserving the persistent deciduous teeth [31-33]. Once these were lost, a prosthetic restoration was provided [34]. Routine removal of impacted teeth was controversially discussed in this connection $[35,36]$ because of potential cyst formation $[32,37]$. The main point usually raised against this approach was the poor quality of the denture bed that resulted from surgical weakening of the alveolar process [38].

At the same time, however, the fact that attempts were made to erupt the impacted teeth with the help of drugs (although these attempts failed) demonstrates that the potential value of teeth not properly erupting but being otherwise healthy had long been recognized [39-41].

Starting in the 1970s, concepts were developed that helped impacted

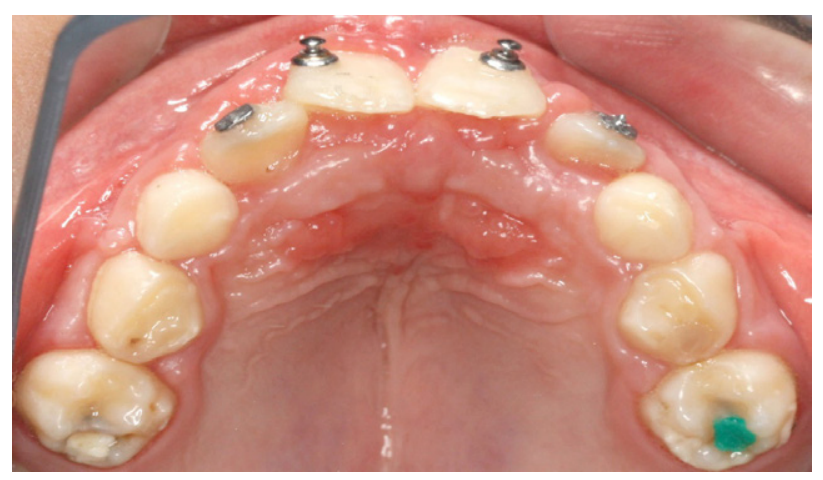

Figure 11b: Occlusal view.

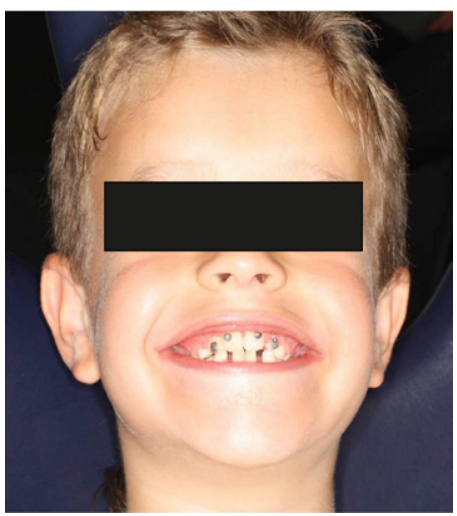

Figure 12a: Situation after mobilization of the four upper incisors: extraoral view, smiling.

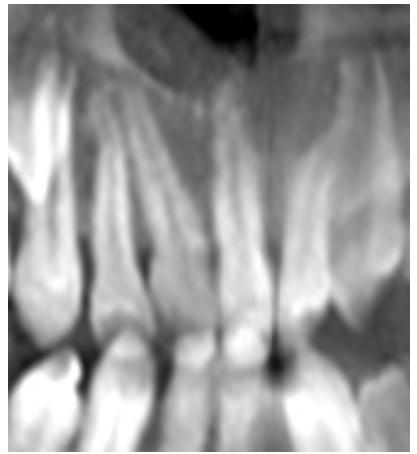

Figure 12b: View of the upper incisor roots in CBCT after mobilization. 
teeth of CCD patients to erupt solely by surgical exposure [20-23]. This strategy turned out to be successful; especially when exposure was accomplished before root growth was completed [11]. The more residual root growth, the higher was the likelihood of spontaneous vertical development of the impacted teeth and the alveolar process. During these procedures, the orthodontist's task was confined to monitor the space available for erupting teeth, with or without the use of space maintainers [11]. Since this strategy was promising in children and adolescents only, the treatment of adults continued to rely mainly on prosthetic restorations.

The eruption of the impacted teeth will also create favorable conditions with regard to prosthetic treatment down the road. An underdeveloped alveolar bone, for example, generally offers not only a poorer denture bed, but an impacted maxillary anterior segment also results in sagittal underdevelopment of the maxillary alveolar process and, hence, in a tendency toward pseudoprognathism. In some situations, promoting the development of tooth eruption will help avoid orthognathic surgical procedures. In this way, major importance must be attached to the mobilization and functional adjustment of impacted teeth in CCD patients even with regard to the jaw position.

It was not until the introduction and continuing development of enamel etching [42], biocompatible metals [43], and biomechanical concepts [44] that active mobilization of impacted teeth (especially group by group) became possible. In addition, the precision of radiographic diagnosis had been enhanced by the introduction and ongoing improvement of three-dimensional imaging techniques [45], creating better conditions for selective mobilization of teeth [46]. This progress is also reflected in the case presented here; CBCT was of enormous benefit for the diagnosis and set the stage for successful treatment - five supernumerary teeth would have gone undetected without this technology. This is relevant because the removal of adjacent supernumerary teeth before root growth is completed will promote the possible eruption of permanent teeth [10]. Also, there is a need to minimize the number of surgical interventions for tooth removal (notably when performed under general anesthesia) and to coordinate their timing with the timing of orthodontic treatment steps.

Impacted teeth can be mobilized with the help of multibracket appliances and rigid archwires if enough space is available and enough teeth are present for anchorage. However, adverse effects, particularly on the adjacent teeth, should be expected in this situation. Experience has shown that detectable intrusive forces on neighboring teeth will occur even during lengthy mobilization attempts performed on single teeth.

The use of a less elastic metal archwire attached to several teeth as performed by Becker [16] may cause the occlusal plane to tilt as a result of intrusive and extrusive side effects, and teeth that get intruded in an uncontrolled fashion may inflict damage on any underlying tooth buds.

While side effects of this type can be eliminated by relying on techniques of skeletal anchorage, the viability of such anchorage is limited in children and adolescents. Interradicular screw insertion is prevented by insufficient bone quality and by the accessional teeth inside the alveolar process, confining the successful placement of anchorage screws to the area of the palate in these patients.

Nor can screws be successfully inserted into the alveolar process of patients who already have reached adult age at the time of presentation [47-49] because of the polyodontia.

A case report dealing with a Japanese CCD patient aged approximately 11 years [12] showed a baseline situation similar to the present case. The Japanese authors, however, designed an anchorage system with teeth and miniscrews as supports in order to mobilize the impacted maxillary anterior teeth. Unlike our own design, the rigid metal archwire was placed palatal to the dental arch, including metal arms extending to the vestibular side to apply tensile force in a physiologically correct caudoventral direction despite its palatal position. The situation in this specific Japanese patient may have been such that confining fixation of the mobilization archwire to teeth only was not an option. Our appliance, however, offers the benefit that the direction of tension can be varied via hooks in the anterior segment of the vestibular archwire. This allows for more precise positioning and shaping of the anterior segment, reducing the time required for followup treatments or eliminating them altogether.

\section{Conclusions}

Simultaneous mobilization of several adjacent teeth in the same direction requires meticulous biomechanical planning, as the larger moment of force can increase the potential side effects on anchor teeth. Consequently, various types of malocclusion can develop whose resolution in itself will require another complicated anchorage system. While supportive skeletal anchorage can compensate for undesirable side effects on teeth (and purely skeletal anchorage can even rule out any dental side effects whatsoever), there are limitations to using skeletal anchorage in CCD patients. Biomechanical considerations therefore remain an essential aspect of orthodontic treatment planning, which is particularly true of complex situations requiring simultaneous mobilization of several impacted teeth.

\section{Acknowledgement}

The authors acknowledge support by Deutsche Forschungsgemeinschaft (DFG) and the Open Access Publishing Fund of Tuebingen University. Furthermore the authors thank Alexander Moumouris of the dental technology laboratory at the Department of Orthodontics of Tübingen University for meticulously manufacturing the appliance and David Schilling, Oliver Borst, Sascha Hoffmann, Andreas Schmidt and Kai Januschowski for fruitful discussions and valuable advice while preparing the manuscript.

\section{References}

1. Scheuthauer G (1871) Kombination rudimentärer Schlüsselbeine mit Anomalien des Schädels beim erwachsenen Menschen. [Combination of rudimentary clavicles and anomalies of the skull in adult humans.] Allg Wien Med Ztg 16: 293-295.

2. Marie $P$, Sainton $P(1898)$ Sur la dysostose cléido-crânienne héréditaire. [About the hereditary dysostosis cleidocranialis.] Rev Neurol 6: 835-838.

3. Hultkrantz JW (1908) Über Dysostosis cleidocranialis. [On dysostosis cleidocranialis.] Z Morphol Anthropol 11: 452.

4. Cole WR, Levin S (1951) Cleidocranial Dysostosis. Br J Radiol 24: 549

5. Järvinen S (1981) Cephalometric findings in three cases of cleidocranial dysostosis. Am J Orthodont 79: 184.

6. Kreiborg S, Jensen BL, Björk A (1981) Abnormalities of the cranial base in cleidocranial dysostosis. Am J Orthodont 79: 549.

7. Fleischer-Peters A (1970) Zur Pathohistologie des Alveolarknochens be Dysostosis cleidocranialis. [On the histopathology of alveolar bone in dysostosis cleidocranialis.] Stoma 23: 212

8. Mundlos S (1999) Cleidocranial dysplasia: clinical and molecular genetics. $J$ Med Genet 36: 177-182.

9. Golan I, Baumert U, Wagener H, Preising M, Lorenz B, Niederdellmann $\mathrm{H}$ et al. (2002) Evidence of Intrafamilial Variability of CBFA1/RUNX2 Expression in Cleidocranial Dysplasia - A Family Study. J Orofac Orthop 63: 190-198.

10. Muessig D, Hirschfelder U, Spitzer W (1991) Behandlungsmaßnahmen be Patienten mit Dysostosis cleidocranialis. [Treatment modalities for patients with cleidocranial dysostosis.] Dtsch Zahnärztl Z 46: 308-312.

11. Tränkmann J (1989) Operativ-orthodontische Einordnung retinierter und 
verlagerter Zähne der zweiten Dentition bei Dysostosis cleidocranialis. [Surgical orthodontic classification of retained and dystopic teeth of the second dentition in dysostosis cleidocranialis.] J Orofac Orthop 50: 316-325

12. Kuroda S, Yanagita T, Kyung HM, Takano-Yamamoto T (2007) Titanium screw anchorage for traction of many impacted teeth in a patient with cleidocranial dysplasia. Am J Orthod Dentofac Orthop 131: 666-669.

13. Lossdörfer S, Abou Jamra B, Rath-Deschner B, Götz W, Abou Jamra R Braumann B, et al. (2009) The role of periodontal ligament cells in delayed tooth eruption in patients with cleidocranial dysostosis. J Orofac Orthop 70 495-510.

14. Baumert U, Golan I, Driemel O, Reichert TE, Reicheneder C, Muessig D, et al. (2006) Dysostosis cleidocranialis - Beschreibung und Analyse einer Patientengruppe. [Dysostosis cleidocranialis - Description and analysis of a group of patients.] Mund Kiefer Gesichtschir 10: 385-393.

15. Miethke RR, Sergl HG, Sernetz F (2003) Lexikon Kieferorthopädischer Begriffe. [Glossary of orthodontic terms.] Quintessenz Verlags $\mathrm{GmbH}$, Berlin.

16. Becker A (1998) The orthodontic treatment of impacted teeth. Martin Dunitz Ltd, London.

17. Yamamoto H, Sakae T, Davies JE (1989) Cleidocranial dysplasia: a light microscope and crystallographic study. Oral Surg Oral Med Oral Path 68: 195200.

18. Shafer WG, Nine MK, Levy BM (1983) A textbook of oral pathology. (4thedn), Saunders, Philadelphia.

19. Tachdjian MO (1990) Pediatric orthopedics. (2ndedn), Saunders Philadelphia.

20. Smylski PT, Woodside DG, Harnett BE (1974) Surgical and orthodontic treatment of cleidocranial dysostosis. Int J Oral Surg 3: 380-385.

21. Hall RK, Hyland AL (1978) Combined surgical and orthodontic management of the oral abnormalities in children with cleidocranial dysplasia. Int J Oral Surg 7: $267-273$.

22. Richardson A, Swinson T (1987) Combined orthodontic and surgical approach to cleidocranial dysostosis. Trans Eur Orthod Soc 63: 23.

23. Behlfelt K (1987) Cleido-cranial dysplasia: diagnosis and treatment concept. Trans Eur Orthod Soc 63: 25

24. Becker A, Lustmann J, Shteyer A (1997) Cleidocranial dysplasia: part 1 general principles of the orthodontic and surgical treatment modality. Am J Orthod Dentofac Orthop 111: 28-33

25. Becker A, Shteyer A, Bimstein E, Lustmann J (1997) Cleidocranial dysplasia: part 2 - a treatment protocol for the orthodontic and surgical treatment modality. Am J Orthod Dentofac Orthop 111: 173-183

26. Mundlos S, Otto F, Mundlos C, Mulliken JB, Aylsworth AS, et al. (1997) Mutations involving the transcription factor CBFA1 cause cleidocranial dysplasia. Cell 89 : 773-779.

27. Zou SJ, D’Souza RN, Ahlberg T, Bronckers ALJJ (2003) Tooth eruption and cementum formation in the Runx2/Cbfa1 heterozygous mouse. Arch Oral Biol 48: $673-677$.

28. Yoda S, Suda N, Kitahara Y, Komori T, Ohyama K (2004) Delayed tooth eruption and suppressed osteoclast number in the eruption pathway of heterozygous Runx2/Cbfa1 knockout mice. Arch Oral Biology 49: 435-442.

29. Callea M, Fattori F, Yavuz I, Bertini E (2012) A new phenotypic variant in cleidocranial dysplasia (CCD) associated with mutation c.391C $<T$ of the RUNX2 gene. BMJ Case Rep; published online 5 Dec 2012.

30. Schwarz AM (1958) Röntgenostatik. Urban \& Schwarzenberg, München.

31. Richter H (1933) Ein Beitrag der Dysostosis cleido-cranialis unter besonderer Berücksichtigung des Zahnsystems. [An article on dysostosis cleidocranialis with a focus on the dental system.] Dtsch Mschr Zahnheilk 18: 817.

32. Hegele E (1954) Zur Dysostosis cleido-cranialis und ihr Verlauf bei einem Kind in acht Jahren Beobachtungszeit. [On dysostosis cleidocranialis and its development in a child during 8 years of monitoring.] [Inaugural Dissertation] Tuebingen (Germany): Eberhard-Karls-University.

33. Andrä A (1960) Ein Beitrag zum Krankheitsbild der Dysostosis cleido-cranialis [An article on the disease pattern of cleidocranial dysostosis.] Dtsch Zahnärzt Z 15: 1313-1315.

34. Magnus WW, Sands NR (1974) Cleidocranial dysostosis. Report of a case. Am J Orthod 65: 638-643.

35. Seldin HM, Seldin DS, Rakower W (1950) Cleidocranial dysostosis. J Oral Surg 8: 236-241.

36. Leff LL (1952) Cleidocranial Dysostosis. J Oral Surg 10: 292-297.

37. Ascher F (1953) Die zahnärztliche Problemstellung bei Dysostosis cleido cranialis. [The dental problem in dysostosis cleidocranialis.] Stoma 88: 5-6.

38. Schiller F (1938) Zur Dysostosis cleidocranialis. [On dysostosis cleidocranialis.] Z Stomat 36: 1212-1223

39. Aronson WA (1928) Über den Einfluss der innersekretorischen Drüsen auf das Wachstum und die Verknöcherung des Knochengerüstes und auf den Durchbruch der Zähne. [On the influence of ductless glands on bone growth and formation and on dentition.] Dtsch Mschr Zahnheilk 46: 759

40. Ascher F (1958) Zur Lösung des zahnärztlichen Problems bei Dysostosis cleidocranialis. [On the solution of the dental problem in dysostosis cleidocranialis.] Dtsch Zahn-Mund-Kieferheilk 29: 31.

41. Jung Ch (1962) Befunde im Zahn- und Kiefersystem bei Dysostosis cleidocranialis. [Findings in the dental and maxillary system in dysostosis cleidocranialis.] Fortschr Kieferorthop 23: 112-115.

42. Buonocore MG (1955) A simple method of increasing the adhesion of acrylic filling materials to enamel surfaces. J Dent Res 34: 849-853.

43. Maijer R, Smith DC (1982) Corrosion of orthodontic bracket bases. Am Orthod 81: 43-48.

44. Smith RJ, Burstone CJ (1984) Mechanics of tooth movement. Am J Orthod 85 294-307.

45. Hirschfelder U, Muessig D, Fleischer-Peters A (1991) Untersuchungen zur Schädelmorphologie bei Dysostosis cleidocranialis. [Analyses of the crania morphology in dysostosis cleidocranialis.] Dtsch Zahnärztl Z 46: 292-296.

46. Dalessandrini D, Laffranchi L, Tonni I, Zotti F, Piancino MG, Paganelli C, et al. (2011) Advantages of cone beam computed tomography (CBCT) in the orthodontic treatment planning of cleidocranial dysplasia patients: a case report. Head Face Med 7: 6.

47. Farronato G, Maspero C, Farronato D, Gioventù S (2009) Orthodontic treatment in a patient with cleidocranial dysostosis. Angle Orthod 79: 178-185.

48. Kamamoto M, Machida J, Miyachi H, Ono T, Nakayama A, Shimozato K, et al (2011) A novel mutation in the C-terminal region of RUNX2/CBFA1 distal to the DNA-binding runt domain in a Japanese patient with cleidocranial dysplasia. In J Oral Maxillofac Surg 40: 434-437.

49. Petropoulos VC, Balshi TJ, Balshi SF, Wolfinger GJ (2004) Treatment of a patient with cleidocranial dysplasia using osseointegrated implants: a patient report. Int J Oral Maxillofac Implants 19: 282-287. 